\title{
DA INEFICÁCIA DO CARÁTER RESSOCIALIZADOR DA PENA PRIVATIVA DE LIBERDADE
}

\author{
Aluno: Nivaldo Alves Soares Júnior \\ RA: $2213204848-8^{\circ} \mathrm{A}$, Diurno, Campus Santo Amaro \\ Orientador: Renata Macedo de Souza
}

RESUMO: $O$ presente trabalho tem o intuito de apresentar as dificuldades que 0 Estado possui para ressocializar o indivíduo que transgride as normas estabelecidas. Neste estudo estaremos trazendo dados estatísticos para facilitar a compreensão das informações trazidas ao longo do trabalho, ilustrando o lado desumano que os encarcerados são obrigados viver durante o cumprimento da pena, ou enquanto litigam em processo judicial, fazendo com que a pena privativa de liberdade tenha o objetivo único de punir o agente que transgride as regras.

Palavras-Chave: Pena privativa de liberdade. Ineficácia do encarceramento. Pena

\section{INTRODUÇÃO}

O sistema prisional brasileiro vive uma situação de colapso absoluto, os estabelecimentos prisionais estão completamente falidos, em situações inóspitas, onde as celas encontram-se na maioria dos presídios em estado de superlotação, além disso, os presídios são "faculdades do crime", pois, o crime organizado domina praticamente todas as penitenciárias brasileiras.

Este trabalho, trará um breve histórico da origem das penas, haja vista, o interesse em saber de onde surge a necessidade da punição aos indivíduos que não respeitavam as regras em civilizações mais primitivas. 
Importante trazer para este estudo a pena privativa de liberdade propriamente dita, sendo assim, podemos trazer a tela deste estudo dados estatísticos sobre a situação geral do cárcere nacional.

Por derradeiro, citaremos neste estudo sobre alguns aspectos do caráter ressocializador da pena privativa de liberdade, que é um dos fatores que apesar do desprezo por parte das autoridades, é sem sombras de dúvida o mais importante fator da pena.

O atual trabalho se finda, com conclusões com base em pesquisas, dados estatísticos e estudos bibliográficos.

\section{Estudo histórico da pena privativa de liberdade}

Desde os primeiros passos da humanidade dentro do convívio social, a coletividade necessita de normas e regras para que se consiga estabelecer a equidade entre os integrantes de um corpo social, porém, quando algum indivíduo presente neste contexto, venha a ignorar as regras estipuladas é de consenso geral que este agente seja punido, desta maneira as mais arcaicas tribos, clãs ou bandos, já possuíam a cultura punitiva.

Porém, não há como ter exatidão do surgimento das Sanções Penais dentro de um período histórico, sendo assim, devemos analisar cada intervalo de tempo relevante.

\subsection{Período das vinganças}

Durante um lapso temporal, temos o denominado "Período das Vinganças", que se iniciou desde o princípio da relação social humana, mesmo que de maneira mais primitiva, até meados do século XVIII, esta etapa da fase evolutiva do direito penal, foi subdividida em três tipos de Vinganças, cada uma com sua característica 
específica, sendo elas: Período da Vingança Privada, Vingança Divina e Vingança Pública.

Mesmo havendo estas diferentes fases, elas não se separam de maneira ordenada, nem uma sucede a outra com um momento exato de mudança, sendo que estas etapas por vezes se misturam, mas ainda assim, é possível notar as diferentes características destes ciclos.

Conforme diz Mirabete:

$\mathrm{Na}$ denominada fase da vingança privada, cometido um crime, ocorria a reação da vítima, dos parentes e até do grupo social, que agiam sem proporção à ofensa, atingindo não só o ofensor, como também todo o seu grupo. Se o transgressor fosse membro da tribo, podia ser punido com a "expulsão da paz" que o deixava à mercê de outros grupos, que lhe infligiram, invariavelmente, a morte. Caso a violação fosse praticada por elemento estranho à tribo, a reação era a da "vingança de Sangue", considerada como obrigação religiosa e sagrada, verdadeira guerra movida pelo grupo ofendido àquele a que pertencia o ofensor, culminando, não raro, com a eliminação completa de um dos grupos (MIRABETTE, 2005, p.35)

Nota-se a violência exagerada nas punições, quando não a pena máxima capital, que poderia levar extermínio completo de uma tribo, ou mesmo a "expulsão da paz", que apesar de não ter um aspecto tão vil quanto à "pena de sangue", deixa o integrante da tribo isolado sujeito às outras tribos.

Uma característica latente da Vingança Privada, era a falta de proporcionalidade, pois, quando o mal era causado a outra parte, agia muitas vezes não só contra o primitivo que havia atentando contra as regras daquele corpo social, mas sim, contra os integrantes da tribo do ofensor e familiares.

Mas com a evolução do raciocínio social humano, começa-se a utilizar um tipo de controle proporcional ao da ação, sendo eles: Lei de Talião e Composição.

A Lei de Talião, era uma espécie de controle moderador da pena, que fazia com que o agente causador da ofensa, sofresse uma pena na mesma proporção do mal gerado ao ofendido, podemos notar vendo alguns dos artigos do Código de hamurabi: 
Art. 195: "Se um filho espanca seu pai, deve-se decepar suas mãos";

Art. 198: "Se alguém arranca o olho de um homem livre, deverá pagar uma moeda de ouro";

Art. 199: "Se alguém arranca o olho de um escravo de outra pessoa, ou quebra um osso do escravo de outra pessoa, deverá pagar a metade do preço deste escravo"; Art. 204: "Se um homem nascido livre espancar outro homem nascido livre, este deverá pagar 10 ciclos de prata".

Fazendo uma breve análise destes artigos, nota-se que apesar de penas extremamente severas, existe uma tentativa de controlar a punição, tendo em vista que este Código seja de aproximadamente 1.780 A.C, já é possível notar uma tentativa de controlar as punições.

De acordo com Teles:

A vingança era privativa do ofendido, do indivíduo vitimado pela conduta do agente, ou de seus sucessores, parentes sanguíneos, que só se afastava se houvesse a composição, vale dizer, se o agente do crime tivesse recursos para, literalmente, "comprar" outra solução (TELES, 2004, vol. 1, p.316).

Podemos perceber nos artigos 198, 199 e 204 do Código de Hamurabi, o pagamento de multa com um aspecto indenizatório, sendo uma outra forma de sanção que vai além do castigo físico.

Com passar dos tempos, outros fatores tendem a incidir sobre as penas, sendo o maior direcionador a vontade divina, ou seja, as penas começam a serem implantadas em nome de Deus, neste momento estamos situados em aproximadamente 1.500 A.C., neste período é necessário que se cumpra as sanções em nome de Deus, para que ele não puna a todos, pois, a prática de atos que não condiziam com os costumes, regras ou regulamentos dentro de um determinado grupo, poderia causar a ira divina, desta forma, havia a necessidade de punir estes ofensores, para que Deus não se virasse contra a coletividade.

Disse Fernandes:

A vingança divina era exercida com redobrada crueldade, eis que o castigo tinha à altura da grandeza do deus 
ofendido e seu propósito era purificar a alma do ofensor, preparando - o para a bem aventurança eterna. $\mathrm{Na}$ realidade, a vingança divina não passava de imposição penal religiosa e sacerdotal (FERNANDES, 2002, p. $651)$.

Com relação a aplicação da pena é que membros de ordem religiosa poderiam aplicar a sanção penal, pois, estes representam a vontade divina.

\subsection{Evolução da pena}

Com a evolução ideológica do homem, é natural que se busque por medidas punitivas mais razoáveis, para ilustrar melhor esta iniciativa, podemos contemplar o período monárquico Romano que é compreendido entre os anos de 753 a.C. até 509 a.C., neste lapso temporal ressalta-se a imponência dos costumes e regras correntes à época, em primeiro momento, há um início marcado por conflitos sociais, sendo de suma importância para o desenvolvimento da Lei das Doze Tábuas, que em breve síntese consistia na origem do direito romano. As leis eram aplicadas por pontífices e representantes da classe dos patrícios, estes por sua vez, eram um nicho da sociedade romana dotada de poder econômico e político, que mantinham as leis em sigilo, pois majoritariamente eram aplicadas contra plebeus.

Outro período de relevante importância que deve ser observado neste estudo, é o de 509 a.C. até 27 a.C., pois até então as leis tratavam das relações interpessoais e a partir deste período, as leis passam a possuir outro viés, pois inicia-se uma era, haja vista as leis começarem a tratar dos interesses do Estado.

Ficando evidenciado o animus do Direito Penal Romano em conquistar um âmbito social, servindo como alicerce para as legislações modernas.

De grande importância também para a contextualização desta parte histórica das penas, é a influência do povo germânico. Com imensa interferência da Europa Central, no sistema penal germânico não possuía um código escrito, restando latente os anseios de suas normas.

Conforme destaca Bittencourt (2006, p.42) "os povos germânicos também conheceram a vingança de sangue, que somente em etapas mais avançadas, com 
o fortalecimento do poder estatal foi sendo gradativamente substituída pela composição voluntária, depois obrigatória".

É importante trazer a esta baila que a aplicação das penas não analisavam a culpa, dolo ou caso fortuito, considerando o dano gerado sendo observada a responsabilidade objetiva em face da subjetiva.

Telles diz que:

[...] antes da invasão Romana, o Direito dos Germanos era consuetudinário, existindo já os delitos públicos praticados contra o interesse coletivo, punidos com a perda da paz pública, o que permitia a qualquer pessoa matar o delinqüente - e os crimes privados, inclusive o homicídio, punidos com a vingança e a composição (TELLES, 2004, P.57).

Sendo assim, é possível notar a importância deste contexto para que se possa vislumbrar como a pena acompanha a evolução social e moral de cada período, é notável o quão alentado é a pena no desenvolvimento das sociedades.

\subsection{Das teorias das penas}

O ponto inicial a ser tratado no estudo da pena, é a diferença com relação à prisão, por vezes, ao ser dita ou ouvida por pessoas leigas, podem ser tratadas como palavras sinônimas, porém, esta relação entre pena e prisão, deve ser apreciada com a cautela necessária para que a sua distinção seja imposta conforme o seu emprego.

É algo comum encontrar os termos pena e prisão em uma espécie de unificação, pois são palavras que tendem a ter um só caminho, que é a punição, mas, é possível verificar que pena e prisão trata-se de gênero e espécie respectivamente. Mas é evidente que o instituto da pena possui uma complexidade enorme dentro do direito penal, pois é tido como a punição por algum ato que implica na necessidade da imposição do Estado.

"Toda lei que não for estabelecida sobre essa base encontrará sempre uma resistência à qual será constrangida a ceder. Assim, a menor força, continuamente aplicada, destrói por fim um copo que 
apareça sólido, porque the comunicou um movimento violento". (BECCARIA, 2017, p.22)

As teorias absolutas possuem conexão com a teoria retributiva. A teoria retributiva é:

"fundada no livre arbítrio - na capacidade de escolha entre o bem e o mal atribuído aos homens -, para a teoria retributiva a pena é um fim em si mesmo". (SILVIA BARROS, 2001, p. 53)

Esta teoria possui o princípio da compensação de culpa, pois ela trata a justa retribuição punitiva ao crime realizado, fazendo com que a culpa do agente seja compensada ao cumprir a pena.

Em um contexto geral, a teoria retributiva não tem muita aceitação, sendo mais comum dentro dos sistemas penais as teorias preventivas da pena, sendo elas aceitas em maior escala.

Pois a teoria preventiva tem como base a prevenção de futuros crimes, principalmente para quem poderia vir a cometer o ato punitivo. Assim esclarece Carmem Silva Barros:

No Estado de direito, voltado para a livre realização do ser, torna- se incompatível qualquer consideração de natureza metafísica - diretamente ligada ao dever moral de punir - na teoria da pena. Assim, viu-se a idéia de fim - diretamente ligada à produção de efeitos úteis para o indivíduo e à coletividade - impor-se sobre as teorias retributivas. E com a prevalência da teoria preventiva, deixa de ser a retribuição o fundamento da reação estatal. O fim justificador passa a ser utilitário e voltado para o futuro. E um direito penal teleologicamente orientado tem como limite os princípios constitucionais (BARROS, 2001, p.56).

Sendo assim, a prevenção tende atingir o indivíduo, usando a intimidação para que o agente não cometa a prática delituosa, esta intimidação se dá, ao causar no agente receio da intervenção do Estado, este pavor, também tem o escopo de evitar que pessoas que de alguma maneira tenham interesse no cometimento de crimes não venha a cometê-los. 
Porém, os dois conceitos mencionados, não completavam o anseio de estudiosos, o que levou ao desenvolvimento de uma teoria, que de alguma forma completasse as lacunas que eram deixadas pelas outras, sendo assim, nasce as Teorias Mistas, também conhecidas como Unificadoras.

Bittencourt diz:

[...] as teorias unificadoras aceitam a retribuição e o princípio da culpabilidade como critérios limitadores da intervenção da pena como sanção jurídico-penal. A pena não pode, pois, ir além da responsabilidade decorrente do fato praticado, além de buscar a consecução dos fins de prevenção geral e especial (BITENCOURT, 2004, p. 143.).

As teorias mistas, buscam englobar os melhores pontos de cada teoria para que se chegasse em apenas um modelo único e justo, buscando uma redução no dano para teorias mais rigorosas.

Nota-se também o surgimento da Teoria da Prevenção Geral, tal conceito visa a execução penal para efetivar a eficácia das normas, fazendo com que se realize a vontade da motivação punitiva satisfatória perante a sociedade.

Assim diz Carmem Silva Barros:

A prevenção geral positiva vem, pois, fundada na afirmação da validade da norma que se obteria com a justa punição do agente. E, dessa forma, através da aplicação e execução da pena seriam satisfeitas as necessidades de punição da sociedade, obtendo-se como resultado a consolidação de comportamentos conformados ao direito. Essa finalidade atribuída à prevenção geral positiva também permite concluir que a pena é mensagem dirigida à sociedade, o agente do crime é ignorado, reduzido a exemplo de uma estratégia de política criminal. Daí a afirmativa de que a prevenção geral positiva representa 0 pensamento retributivo modificado (BARROS, 2001, p.62/63) 
Nota-se que há algo comum entre este instituto e a ideia de retribuição, sendo a pena um exemplo para o coletividade, assim, vindo a inibir qualquer vontade de cometimento de ilícitos puníveis.

\section{Da pena privativa de liberdade}

Com a evolução social, nasce a preocupação com as punições impostas aos transgressores das normas, haja vista, castigos físicos e até mesmo a pena capital, serem adotadas de maneira corriqueira em grande parte do Planeta. Desta forma, a sociedade, não se preocupa apenas em punir os delinquentes, mas que de alguma maneira, estes fiquem isolados da sociedade e voltem quando estiverem aptos a retornarem ao convívio social.

Para esta questão, o direito penal institui a Pena Privativa de Liberdade, sendo que de início a intenção é apenas isolar o indivíduo dos demais integrantes da sociedade, porém, com o surgimento dos direitos humanos, alguns outros objetivos surgem, não ficando restrito unicamente a punição, mas também, a tentativa de ressocializar o infrator.

\subsection{Da superlotação nos presídios}

A pena privativa de liberdade tornou-se o meio mais popular até os dias contemporâneos para a punição dos infratores, independente das questões religiosas ou econômicas de determinada região. Porém, é evidente que o nível de tratamento dos indivíduos encarcerados, determine a situação com que este indivíduo retorne ao convívio social.

Atualmente, é fácil constatar problemas relativos a esta modalidade de pena, pois, em primeiro lugar, percebemos o quão oneroso ao Estado é manter um prisioneiro, haja vista, a média do valor mensal gasto com cada preso é de 
aproximadamente $R \$ 2.400,00$ (dois mil e quatrocentos reais) ou seja por ano os cofres públicos têm um gasto de aproximadamente $R \$ 20.929 .305 .600,00$ (vinte bilhões novecentos e vinte e nove milhões trezentos e cinco mil e seiscentos reais), ao colocarmos o Brasil, dentro desta análise iremos vislumbrar, que esta nação possui a $3^{a}$ maior malha carcerária conforme diz o Departamento Penitenciário Nacional com aproximadamente 726.712 presos, dados de junho de 2018, perdendo apenas para China, que é bom ressaltar possui uma população demográfica de aproximadamente 1.3 bilhão de pessoas e para os Estados Unidos da América, que também, é detentor de uma demografia maior que a brasileira com pouco mais de 325 milhões de habitantes, sendo que 2,3 milhões encontram-se presos.

Quando as penas são muito severas, costuma-se existir uma maior probabilidade de superlotação dentro dos estabelecimentos prisionais, o sistema penal brasileiro, costuma encarcerar os litigantes em processos penais, aumentando ainda mais a população carcerária, mesmo havendo uma tentativa de diminuição o número de litigantes já presos no Brasil é muito elevado, mas, em 2015 o Conselho Nacional de Justiça, juntamente com o Tribunal de Justiça de São Paulo, inseriram no processo penal a audiência de custódia, que tem como objetivo levar o preso em flagrante o mais rápido possível para uma audiência com o juízo, cabendo a este analisar os aspectos da prisão e a necessidade da manutenção do réu no cárcere.

\subsection{Da baixa escolaridade da população carcerária}

Entre muitos fatores que interligam os presos no Brasil, algo que deveria ser muito melhor apreciado pelas autoridades e por vezes são completamente ignorados, é o baixo grau de escolaridade dos encarcerados brasileiros. Pois, em uma população carcerária de aproximadamente 726 mil presos no Brasil, um dado impressionante é que apenas $8 \%$ ou seja algo em torno de 58 mil presidiários, apenas possuem o ensino médio completo, no mesmo tocante, $1 \%$ deste total de presos possuem ensino superior. (Fonte: INFOPEN) 
Desta maneira é impossível ignorar que a baixa escolaridade não seja um "gatilho" ao cometimento de crimes, principalmente os crimes contra o patrimônio e de tráfico de drogas. Neste sentido a relação crimes com baixa escolaridade, por vezes parece ser fator completamente ignorado pelos governantes, portanto seria interessante que poder público atentasse para este fator.

Sendo assim, é notório que o ensino deficitário no país, alavanca os índices criminais no país, fazendo com que os sistemas prisionais estejam sempre lotados de delinquentes ou excluídos da sociedade.

\section{Caráter ressocializador da pena privativa de liberdade}

Como foi ilustrado anteriormente, a pena não possui o cunho único de punir o agente que transgride as normas impostas, mas também, cabe a aplicação da pena, para que o delinquente, seja ressocializado, sendo reinserido na sociedade, sem que venha a praticar novos crimes, porém, não é o que se nota, o Brasil, é detentor de um dos maiores índices de reincidência criminal do mundo, deixando evidente o quão falho é o sistema prisional neste escopo penal.

É impossível imaginar a convivência pacífica entre os homens, sem a existência da pena privativa de liberdade, pois, é de suma importância para a harmonia da sociedade punições aos delinquentes, mas todavia, é necessário examinar os resultados da aplicação de tão severa punição, para que assim, seja possível analisar a sua eficácia. No entanto, os números não são satisfatórios, pois, grande parte dos encarcerados, são reincidentes, fato que torna claro, que apenas retirar o indivíduo do convívio social, não seja garantia de que a punição será suficiente para readequar a conduta social do agente.

A reincidência no Brasil, é de cerca de $70 \%$, ou seja, se fizermos uma conta para analisarmos esta porcentagem, veremos que 508.200, aproximadamente, ao saírem dos complexos carcerários, irão cometer novo crime, um número que deveria ser levado a sério pelo Estado. 


\subsection{O estigma do cumprimento da pena}

De longa data, a sociedade tende a rotular algumas pessoas, pela sua condição social, aparência, cor da pele, opção sexual entre outras diversas formas de pré-julgar qualquer indivíduo. Nesta toada, podemos incluir a figura do "EX-PRESIDIÁRIO", pois, esta pessoa, além de todo o seu sofrimento dentro do cárcere, ao retornar para o convívio social, é duramente hostilizado pelo mercado de trabalho, sendo uma operação de alta complexidade conquistar um emprego.

Logo, quando está egresso à sociedade, um dos grandes dilemas do ex-presidiário é a busca de um novo emprego, haja vista, este estigma de criminoso não sair do cidadão que cumpre ou cumpriu pena, desta forma, o rol de opções de trabalho é muito curto para não dizer inexistente.

Desta maneira, sendo detentor desta negativa marca, o "ex-presidiário", inicia uma nova tentativa de convívio social, as margens da sociedade, onde, não consegue estabelecer vínculo empregatício, sendo assim, o resultado tende a ser desfavorável com relação a ressocialização do indivíduo, a respeito disso Zaffaroni diz:

A carga estigmática produzida por qualquer contato do sistema penal, principalmente com pessoas carentes, faz com que alguns círculos alheios ao sistema penal aos quais proíbe a coalizão com estigmatizados, sob pena de considerá-los contaminados, comportem-se como continuação do sistema penal. Cabe registrar que a carga estigmática não é provocada pela condenação formal, mas pelo simples contato com o sistema penal. Os meios de comunicação de massa contribuem para isso em alta medida, ao difundirem fotografias e adiantarem-se às sentenças com qualificações como "vagabundos", "chacais", etc (2001, p. 134).

Os próprios órgãos estatais nos editais dos concursos públicos, não permitem o acesso de egressos do sistema prisional, servindo de espelho para as empresas privadas, tornando o "ex-presidiário" em um criminoso em potencial, haja vista, as necessidades pecuniárias estarem presentes a todo momento na vida de qualquer cidadão, inclusive de quem já cumpriu pena, mas com um óbice maior que é a marca deixada pelo sistema penal. 
Sem sombras de dúvidas, isto é um fator que aumenta exponencialmente o indivíduo a praticar novo delito, gerando um círculo entre, liberdade e prisão, pois, a cada nova prisão, fica muito mais difícil de se recuperar o cidadão, ainda mais, quando temos um Estado inerte que pouco faz para os cidadãos de "bem", quanto mais para os tidos como "bandidos".

\subsection{Educação dentro dos estabelecimentos prisionais}

Conforme ilustrado neste estudo, o índice de escolaridade dos encarcerados no Brasil é absurdamente baixo, o que em muitos casos ilustra algum tipo de abandono do Estado, e como é de conhecimento geral que os estudos são o ínicio de boas oportunidades, talvez, trazer a estas pessoas, ensino de boa qualidade com cursos profissionalizantes, enquanto cumprem suas penas ou aguardam o desfecho de suas situações processuais, seria uma medida, que pudesse trazer algum resultado.

Pois, se o delinquente ingressar no estabelecimento prisional com o ensino fundamental apenas, e sair de lá com ensino médio e uma profissão adquirida por meio de um curso profissionalizante, o Estado estaria trazendo a esta pessoa uma oportunidade, haja vista, este indivíduo ter que lutar contra o estigma de "bandido", ao menos, teria um pouco de educação, e conhecimento técnico para buscar o seu lugar no mercado de trabalho e assim, conquistar a sua dignidade.

Porém, sabemos o quanto esta medida traria de custos ao erário, e com uma opinião pública, que provavelmente não aceitaria com bons olhos este investimento, o governo nem sequer cogita algo neste tocante, pois, em um país onde presos são submetidos a tratamentos desumanos em determinados locais ficando em containers, não é de se esperar que o investimento na causa prisional seria visto de maneira interessante. 


\section{CONCLUSÃO}

Este trabalho, teve como propósito o estudo do caráter ressocializador da pena privativa de liberdade, com análise dos dispositivos contidos em lei.

A intenção é apresentar o cenário crítico dos estabelecimentos prisionais, e sentir se a aplicação da pena privativa de liberdade é uma maneira eficaz para a recuperação do indivíduo transgressor das normas, pois a atual aplicação da pena privativa de liberdade, não é capaz de recuperar o delinquente, conforme ilustrou dados estatísticos ao longo do trabalho.

Este tema foi escolhido devido ao caos penal dos dias atuais, nos últimos anos, massacres que chocam e viram notícias no mundo inteiro, a superlotação, o domínio das organizações criminosas, a ociosidade dos encarcerados, tudo fomenta uma crise que tem por tendência piorar ao longo dos anos.

Foi apresentado neste trabalho uma breve ilustração da história da pena, onde é trazido à baila a origem da punição, ainda estudamos sobre a teoria da pena analisando algumas delas, também, é estudado a pena privativa de liberdade propriamente dita, também é apresentado o critério ressocializador da pena, sendo o maior foco deste trabalho.

E ainda por derradeiro, foi apresentado uma medida para o auxílio na recuperação dos encarcerados, que seria a implementação de ensino nos estabelecimentos prisionais, sendo que tal fato poderia ser uma das poucas soluções para o reencontro da dignidade com o apenado.

\section{REFERÊNCIAS BIBLIOGRÁFICAS:}

BARROS, Carmen Silvia de Moraes. A Individualização da Pena na Execução Penal. São Paulo: RT, 2001

BECCARIA, Cesare Marquês. Dos delitos e das penas

BITENCOURT, Cezare Roberto. Tratado de direito penal parte geral vol.1

CAPEZ, Fernando. Curso de direito penal parte geral (ART. $1^{\circ}$ a $120^{\circ}$ ) 
FERNANDES, Newton. Criminologia integrada $2^{\mathrm{a}}$ ed.

MARQUES, Oswaldo Henrique Duek. Fundamentos da pena

MASON, Cleber. Direito penal parte geral - (ART. $1^{\circ}$ a $\left.120^{\circ}\right)$

NUCCI, Guilherme de Souza. Código penal comentado

TELES, Ney Moura. Direito penal parte geral art. $\left(1^{\circ}\right.$ a $\left.120^{\circ}\right)$

ZAFFARONI, Eugenio Raúl; PIERANGELI, Jose Henrique. Manual de direito penal brasileiro: volume 1: parte geral. $9^{\circ}$ ed. rev. e atual. São Paulo: Revista dos Tribunais, 2001. 